\title{
Full Length Research Article \\ Relationship between Fasting Plasma Glucose and Glycated Haemoglobin In Adult Diabetic Nigerians
}

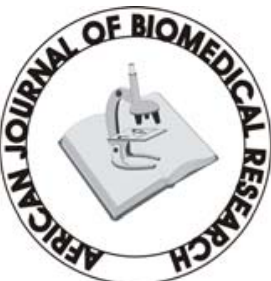

Full-text available at http://www.ajbrui.com http://www.bioline.br/ http://www.ajol.com

Received:

December 2006

Accepted

(Revised):

March 2007

Published

May 2007

\author{
IAkinloye O.A, ${ }^{2} *$ Adaramoye O.A, ${ }^{3}$ Akinlade K.S, ${ }^{2}$ Odetola A. A. \\ and ${ }^{4}$ Raji A.A. \\ ${ }^{1}$ Department of Chemical Pathology, College of Health Science, Ladoke Akintola \\ University of Technology, Osogbo, Osun State. Nigeria. \\ ${ }^{2}$ Department of Biochemistry, Faculty of Basic Medical Sciences, College of \\ Medicine, University of Ibadan, Ibadan. Oyo State. Nigeria. \\ Departments of ${ }^{3}$ Chemical Pathology and ${ }^{4}$ Hematology, University College \\ Hospital, Ibadan. Oyo State. Nigeria.
}

\section{ABSTRACT}

The relationship between packed cell volume (PCV), fasting plasma glucose (FPG) and glycated haemoglobin $\left(\mathrm{HbA}_{\mathrm{I}}\right)$ was investigated in 40 diabetic patients (22 males and 18 females) and 20 apparently healthy controls (12 males and 18 females). Among the control subjects the FPG and HbA1 were significantly higher in the female than male subjects $(\mathrm{P}<0.001)$. This gender differences was not found in diabetic patients $(\mathrm{P}<0.05)$. While all the control subjects have FPG and HbA1 level within normal range (75- $115 \mathrm{mg} / \mathrm{dl}$ and $5-8 \%$, respectively), 15 (38\%) of the diabetic patients had FPG level within normal and only 5 (13\%) had HbA1 level within the normal range. The FPG and HbA1 values were however, significantly higher in diabetic patients $(139.34 \pm 7.06$ and $12.09 \pm 2.80)$ than control subjects (76.40 \pm 1.24 and $6.24 \pm 0.51)$, respectively $(\mathrm{P}<0.001)$. The PCV in controls correlated significantly with FPG and HbA1 (P < 0.001) while the FPG correlated significantly with HbA1 $(\mathrm{P}<0.001)$. There was however only a significant correlation between FPG and HbA1 in the diabetic subjects. Bland Ahman graph shows a good agreement between FPG and HbA1, in both test and control subjects. These results show that PCV and gender factors have significant influence on FPG and HbA1 level in control subjects and were insignificant in diabetic patients. FPG and / or HbA1 are important and agreeable indices for assessment of glucose metabolism. Furthermore, there was an evidence of poor glycemic control in diabetic patients investigated in this study, probably due to poor compliance culture of the patients or inability to procure recommended drugs.

(Afr. J. Biomed. Res. 10: 127 - 132)

*Address for Correspondence: aoadaramoye@yahoo.com and ao.adaramoye@mail.ui.edu.ng

Abstracted by:

African Index Medicus (WHO), CAB Abstracts, Index Copernicus, Global Health Abstracts, Asian Science Index, Index Veterinarius, Bioline International , African Journals online 


\section{INTRODUCTION}

Diabetes mellitus is a metabolic disorder characterized by raised plasma glucose levels. The relatively ineffective insulin in this condition results in hyperglycemia. Diabetes is becoming a major health problem in Nigeria with a prevalence of 1.4 2.7\% (Erasmus et al., 1988; Ngumah, 1995; Bakari et al., 1999) and over $90 \%$ of these are non-insulin dependent (NIDDM) (Ohwworiole et al., 1988; National survey, 1997). Insulin enhances the entry of glucose into the tissue cells, where it is metabolized to produce energy. Excess cellular glucose is stored as glycogen, which may be catabolized in time of need. However, the presence of excess glucose circulating in the blood results in potential pathological complications (Morris et al., 1990; Philips et al., 1999). Diabetes causes prolonged ill - health, impose morbidity and mortality risk (Wokoma, 1999; Erasmus et al., 1999), necessitates a change in lifestyle with a meticulous daily routine and long - term self care with committed compliance to patients care plan (Bille, 1986; Hughes, 1987). Excess circulating glucose in diabetes is a reactant molecule that is involved in the glycosylated atom of other biomolecules and tissues. Glycosylation of haemoglobin is particularly popular and of great clinical importance. Glycated haemoglobin $\left(\mathrm{HbA}_{1}\right)$ expressed as a percentage of total blood haemoglobin concentration gives a retrospective assessment of the mean plasma glucose concentrating during the preceding $6-8$ weeks. Its measurement is therefore discussed as good method of assessing glycemic control (Nathan, 1995; Dandson and Schriger, 1999). The higher the percentage of circulating HbA1in the diabetes, the poorer the mean diabetic control.

In the current study, FPG was correlated with HbA1 in order to investigate the possible relationship between FPG and $\mathrm{HbA}_{1}$ in established diabetic patients in Nigeria. The possible influence of gender and PCV was also investigated. This study also attempts to reveal the level of compliance of patients in this environment to diabetic care/control measures.

\section{MATERIALS AND METHODS}

Subjects: Twenty non-diabetic healthy looking subjects (12 males, 8 females) and forty diabetic patients (22 males, 18 females) attending medical out patient clinic (MOP) and metabolic research ward of Department of Chemical Pathology, University College Hospital Ibadan were recruited into this study. About $6-10 \mathrm{mls}$ of venous blood, fasting sample was collected and distributed into fluoride oxalate bottles for fasting plasma glucose (FPG), Lithium heparin bottle for Glycosylated haemoglobin $\left(\mathrm{HbA}_{1}\right)$ and Ethylenediamine Tetraacetic Acid (EDTA) bottles for packed cell volume (PCV) estimation.

Methods: Packed cell volume (PCV) was estimated by micro haematocrit method as described by Dacie and Lewis, (1991), while the Fasting Plasma Glucose (FPG) was estimated by glucose oxidaseprotein precipitation (GOD-PAP) enzymatic colorimetric method of Barham and Trinder, (1972). Glycosylated haemoglobin was determined in whole blood using the ion-exchange resin method of Nathan, (1984) Briefly, the technique explores the ion charge on $\mathrm{HbA}_{1}$ to separate it from normal $\mathrm{HbA}$. At the analytical $\mathrm{pH}$ the normal haemoglobin fraction $(\mathrm{HbA})$ is retained by the ion-exchange resin, while the glycosylated haemoglobin fraction $\mathrm{HbA}_{1}$ has a net charge that will make it to remain in the supernatant. The rapid phase separation with the aid of plastic separator, separate the resin from supernatant, allowing a quick evaluation of the relative proportion of $\mathrm{HbA}_{1}$ with respect to total HbA. The optical density of each proportion was then measured spectrophotometrically.

Statistical Analysis: Statistical Package for Social Sciences Software (SPSS) was used for the analysis of results. The results were expressed as means \pm S.D. The paired " $t "$ test was used to determine significant difference between test and control subjects. Statistical significant level was put at $\mathrm{P}<$ 0.05. Relationships between the investigated parameters were established using Pearson's correlation. 


\section{RESULTS}

The means \pm S.D. of packed cells volume (PCV), fasting plasma glucose (FPG) and glycosylated haemoglobin $\left(\mathrm{HbA}_{1}\right)$ were presented in Table 1 . This parameter was compared between test and control subjects using paired sample "t" test. There was significant increase in FPG and $\mathrm{HbA}_{1}$ of diabetic patient compared with control $(\mathrm{t}=8.78$ and 12.77 respectively, $\mathrm{P}<0.01)$. However, there was no significant difference in their PCV $(\mathrm{t}=1.39, \mathrm{P}>$ 0.05). Table 2 shows a significant increase in PCV of male control subjects compared with female ( $\mathrm{P}<$ $.001)$ and a significant decrease in FPG and $\mathrm{HbA}_{1}(\mathrm{P}$ $<.001)$. This gender differences was however not observed in diabetic patients.

Using Pearson's correlation statistical method, gender difference (sex) shows significant positive correlation with PCV, FPG and $\mathrm{HbA}_{1}(\mathrm{r}=0.828$, 0.912 and 0.914 respectively, $\mathrm{P}<0.01$ ) in control subjects. There was also a positive correlation between FPG and $\mathrm{HbA}_{1}(\mathrm{r}=0.723, \mathrm{P}<0.01)$. There was no correlation between gender (sex) and these parameters in test subjects, but FPG correlated positively with $\mathrm{HbA}_{1}(\mathrm{r}=0.616, \mathrm{P}<0.01)$. Furthermore, Bland Ahman graph shows agreement between FPG and $\mathrm{HbA}_{1}$ both in diabetes and control subjects (Figures I and II).

\section{Table 1:}

Packed Cell Volume (PCV), Fasting Plasma Glucose (FPG) and Glycosylated haemoglobin $\left(\mathrm{HbA}_{1}\right)$ in test and control subjects

\begin{tabular}{llllll}
\hline Parameters & Test & Control & "t" & p \\
\hline PCV & 42.55 & $39.0 \pm$ & 1.39 & $\mathrm{P}>$ \\
& \pm 4.11 & 1.41 & & & 0.05 \\
\hline FPG & 139.34 & 26.40 & \pm & 8.78 & $\mathrm{P}>$ \\
& \pm 7.06 & 1.25 & & & 0.01 \\
\hline $\mathrm{HbA}_{1}$ & 12.09 & 6.24 & \pm & 12.77 & $\mathrm{P}>$ \\
& \pm 2.80 & 0.51 & & & 0.01 \\
\hline
\end{tabular}

Values expressed as means \pm S.D.

Table 2:

Packed Cell Volume (PCV), Fasting Plasma Glucose (FPG) and Glycosylated haemoglobin (HbA 1 ) compared in male and female subjects.

\begin{tabular}{|c|c|c|c|c|c|}
\hline CONTROL & SEX & $\mathbf{N}$ & Mean :t SD & "t" & $\bar{P}$-Value \\
\hline \multirow[t]{2}{*}{ AGE } & MALE & 12 & $46.17: t 12.92$ & 0.89 & $\mathrm{P}>0.05$ \\
\hline & FEMALE & 8 & $50.75: t 16.13$ & & \\
\hline \multirow[t]{2}{*}{ PCV } & MALE & 12 & $44.00: t 3.57$ & 6.15 & $\mathrm{P}>0.001$ \\
\hline & FEMALE & 8 & 35.75 :t 2.45 & & \\
\hline \multirow[t]{2}{*}{ FPG } & MALE & 12 & 72.33 :t 2.15 & 8.99 & $\mathrm{P}>0.001$ \\
\hline & FEMALE & 8 & 92.50 :t 2.17 & & \\
\hline \multirow[t]{2}{*}{ HbAI } & MALE & 12 & 5.87:t 0.21 & 11.09 & $\mathrm{P}>0.001$ \\
\hline & FEMALE & 8 & 6.80 :t 0.11 & & \\
\hline \multicolumn{6}{|l|}{ TEST } \\
\hline \multirow[t]{2}{*}{ AGE } & MALE & 22 & 55.42:t 7.19 & 1.66 & $\mathrm{P}>0.05$ \\
\hline & FEMALE & 18 & 60.19 :t 8.59 & & \\
\hline \multirow[t]{2}{*}{ PCV } & MALE & 22 & 43.18:t 4.25 & 1.09 & $\mathrm{P}>0.05$ \\
\hline & FEMALE & 18 & 41.78 :t 3.91 & & \\
\hline \multirow[t]{2}{*}{ FPG } & MALE & 22 & 131.55 :t 45.29 & 1.23 & $\mathrm{P}>0.05$ \\
\hline & FEMALE & 18 & 148.83 :t 43.15 & & \\
\hline \multirow[t]{2}{*}{ HbAI } & MALE & 22 & 11.59:t 3.11 & 1.29 & $\mathrm{P}>0.05$ \\
\hline & FEMALE & 18 & 12.69 :t 2.19 & & \\
\hline
\end{tabular}


Table 3:

Correlation between the Parameters in Diabetes Patients and Control Subjects

\begin{tabular}{llllll}
\hline CONTROL & SEX & AGE & PCV & FPG & HBA1 \\
\hline SEX & - & $\mathrm{r}=0.215$ & $\mathrm{r}=0.828^{* *}$ & $\mathrm{r}=0.912^{* *}$ & $\mathrm{r}=0.914^{* *}$ \\
\hline AGE & $\mathrm{R}=0.215$ & - & $\mathrm{r}=0.148$ & $\mathrm{r}=0.292$ & $\mathrm{r}=0.211$ \\
\hline PCV & $\mathrm{R}=0.828^{* *}$ & $\mathrm{r}=0.148$ & - & $\mathrm{r}=0.717^{* *}$ & $\mathrm{r}=0.723^{* *}$ \\
\hline FPG & $\mathrm{R}=0.912^{* *}$ & $\mathrm{r}=0.292$ & $\mathrm{r}=0.716^{* *}$ & - & $\mathrm{r}=0.982^{* *}$ \\
\hline HbAI & $\mathrm{R}=0.914$ & $\mathrm{r}=0.311$ & $\mathrm{r}=0.723^{* *}$ & $\mathrm{r}+0.982^{* *}$ & - \\
\hline TEST & & & & $\mathrm{r}=0.195$ & $\mathrm{r}=0.197$ \\
\hline SEX & - & $\mathrm{r}=0.343$ & $\mathrm{r}=0.172$ & $\mathrm{r}=0.090$ & $\mathrm{r}=0.020$ \\
\hline AGE & $\mathrm{r}=0.343$ & - & $\mathrm{r}=0.107$ & $\mathrm{r}=0.101$ & $\mathrm{r}=0.206$ \\
\hline PCV & $\mathrm{r}=0.172$ & $\mathrm{r}=0.107$ & - & - & $\mathrm{r}=0.616^{* *}$ \\
\hline FPG & $\mathrm{r}=0.195$ & $\mathrm{r}=0.090$ & $\mathrm{r}=0.101$ & $\mathrm{r}=616^{* *}$ & - \\
\hline HbAI & $\mathrm{r}=0.197$ & $\mathrm{r}=0.020$ & $\mathrm{r}=0.020$ & \\
\hline
\end{tabular}

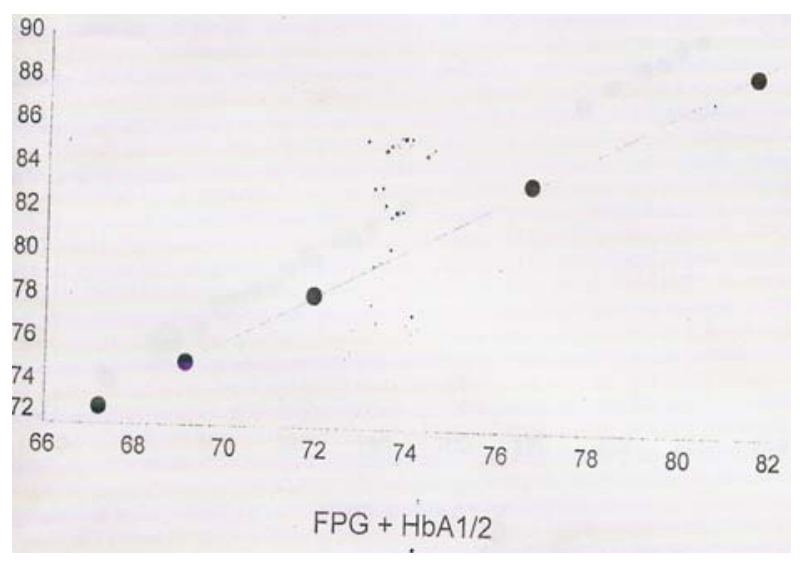

Figure 1:

Bland Altman Graph showing Agreement between FPG and $\mathrm{HbAl}$ in non-diabetics (Control subjects).

\section{DISCUSSION}

In developing countries the only means of screening for diabetes or monitoring its treatment is by determination of fasting plasma glucose concentration (Dandson and Schriger, 1999). The role and importance of glycated heamoglobin in the long-term assessment of diabetic patients has been recognized and appreciated (Malik et ai., 1996).

This study demonstrated a good agreement between these two parameters in the assessment of glucose metabolism in the diabetes.

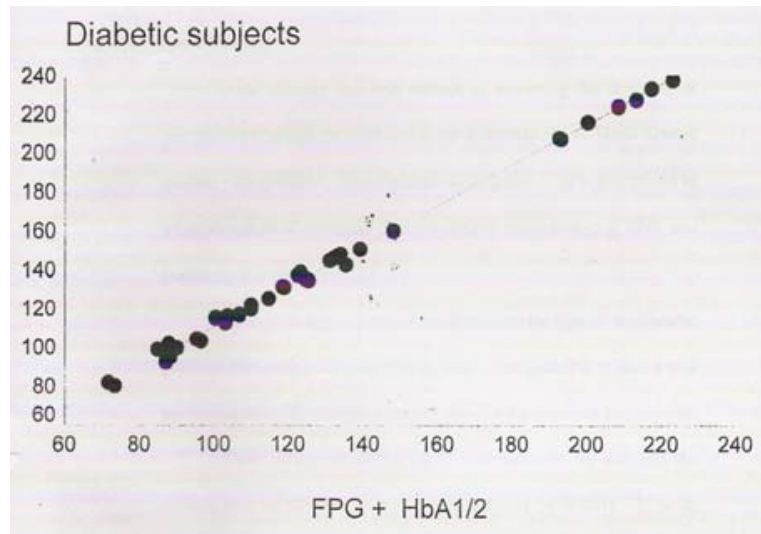

Figure 2:

Bland Altman Graph showing Agreement between FPG and $\mathrm{HbA}_{1}$ in diabetes (Test subjects).

A significant positive correlation was found both in diabetic patients and control subjects $(\mathrm{r}=0.616$ and 0.982 respectively, $\mathrm{P}<0.001)$. This indicates that the higher the fasting plasma glucose the higher the glycated haemoglobin and thus implies that glycosylation of haemoglobin increases with increase in plasma glucose. It is of interest to note that gender difference and packed cell volume (PCV) of subjects correlated significantly with FPO and $\mathrm{HbAI}(\mathrm{P}<0.001)$ in control subjects. It is an established fact that PCV is generally higher in males than in females (Dacie and Lewis, 1991). This is consistent with the observation of the present 
study. However the relationship among PCV, FPO and $\mathrm{HbA}$ ) in control and diabetic subjects has not been established. In this study, significant gender differences were found in FPO and HbAI of control subjects. FPO and $\mathrm{HbA}$ ) were significantly higher in females than males. This may be due to lower packed cell volume in females, implying lower haemoglobin available for glycosylation and probably more plasma fraction of blood and hence more plasma glucose compared to male. This may be partially responsible for better glycemic control in male type 2 diabetic patients compared to females as reported by Valle et ai., (1999) Interestingly, this gender difference in FPO and $\mathrm{HbA}_{\mathrm{I}}$ was not observed in diabetic patients. This implies that the influence of gender (sex) and PCV on glucose metabolism is loss in diabetic patients. FPO and HbAI is therefore solely a representative of glucose metabolism in adult diabetes. This is further established by significant correlation between these parameters ( $\mathrm{r}=$ $0.616, \mathrm{P}<0.001)$. The evidence available in this study may however not be able to prove that the same will be applicable to anemic patients, a very common problem in the tropics. The main use of glycated haemoglobin is to assess long - term glycemic control in the management of diabetic patients, to provide valuable informat $i<$ :m about the average blood glucose levels over the previous 1-2 months and to monitor compliance of patients to treatment regimens (Goldstein et al., 1982 \& 1986; Meidema and Casparie, 1984; Lester, 1989)

In this study, while all the control subjects have FPG and HbA) levels within normal range (75$115 \mathrm{mg} / \mathrm{dl}$ and $58 \%$, respectively). About 15 (38\%) of the diabetic patients have FPG within normal range and 28 (70\%) have FPG below $140 \mathrm{mg} / \mathrm{dl}$, borderline for diabetes. Only 5 (13\%) have HbAI within normal range (5 - 8\%). There is a possible indication of poor glycemic control in the diabetic patients investigated in this study. This probably implies that these patients only prepared themselves for clinic days. This is consistent with the observation of Watkins, (1993).

In conclusion, there is a good agreement and strong relationship between FPG and HbA]. Gender (Sex) and PCV influences FPG and HbA) in non diabetes subjects but this influence is loss in diabetic patients. FPG and HbA, are therefore, main factors of monitoring glucose metabolism in diabetes. This study reveals a poor glycemic control in patients investigated and possibly poor culture of diabetes care.

\section{REFERENCES}

Bakari AG, Onyemehike GC, Sani BG, Hassan SS, Aliyi TM (1999): Relevance of diabetes in suburban northern Nigeria: results of a public screening survey. Diab. Int. 1999; 9: 59 - 60.

Barham, D., Trinder, P. (1972). GOD- PAP enzymatic colorimetric method of glucose estimation without deproteinization. Analyst 97,312- 322

Bille D.(1986): Tailoring your diabetic patients case plan to fit his lifestyle. Nursing 1986:16:55 -7.

Dacie JV and Lewis SM (1991). Determination of packed cell volume (PCV or haematocrit volume) in practical haematology. PP. 48- 59. Seventh edition, Churchill Living stone, NY.

Dandson MB, Schriger D.L (1999) Relationship between fasting plasma glucose and glycosylated haemoglobin. Journal of the American Medical Association 1999,281 (13): 1203 -10.

Erasmus RT, Ebonyi E., Fakeye T. Prevalence of diabetes mellitus in rural Nigeria Population. Nig.Med Pract. 1988, 15, 22 - 6.

Erasmus RT, Blanco EV, Okesina AB, Mesa J (1999). Hypertension, Proteinuria and renal insufficiency in black south Africans with non - insulin dependent diabetes. Diab. Int. 1999,9: 57 - 8.

Goldstein D.E., Little RR, Wedmeyer RM. England JD, MckenzIe E.M. (1986). Glycated

haemoglobin Methodologies and Clinical Implications. Clin Chern. 32 (Suppll0): B64-B20.

Goldstein DE, Wiedmeyer HM, England JD, Little RR, Parker KM. (1982) Glycosylated protein in whole blood spotted on filter paper. Clin Chern. 28(2): 386-7

Hughes B (1987). Diabetes Management. Nursing 17: 63 - 4.

Lester E. (1989) The Clinical Value of glycated haemoglobin and glycated plasma proteins. Ann Clin Biochem 26: 213-219.

Malik, M., Gill, G.V., Heynigden, C.V., Pugh, R.N. (1996). Assay Methods for glycated haemoglobin: A review for tropical hospitals International Diabetes Digest, 7: No.1 Jan.

Meidema K, Casparie T. (1984) Glycosylated haemoglobin: biochemical Evaluation and Clinical Utility. Ann Clin Biochem 21:2-15.

Morrish NJ, Sterens NK, Head J., Fuller JH, Jarrett RJ, Keen H (1990). A prospective study of mortality 
among middle - aged diabetes patients (The London cohort of the WHO multinational study of vascular disease in diabetes) 1.Causes and death rates. Diabetologia 1990,33(9): 538-541.

Nathan D.M (1999): Estimation of glycosylated haemoglobin. New England Journal of Medicine 310, 341 - 346.

(1999) Estimation of Glycosylated Haemoglobin. New England Journal of Medicine 310, 341-346.

Ngumah QC (1995). The role of optometrists in screening for diabetics in Nigeria. Int. Diab Dig 1995; 6: 37 - 8.

Ohwworiole AE, Kuti JA, Kabiawu SID (1988). Casual blood glucose levels and prevalence of undiscovered diabetes mellitus in Lagos metropolis Nigeria. Diabetes
Res. Clin. Pract. 1988; 4: 153 - 8.

Philips A, Janssen U, Floege J. (1999) Progression of diabetes nephropathy, Insight from cell studies and animal models. Kidney Blood Press Res 1999:22:81 - 97.

Valle T, Koivisto V.A, Reunanen A, Kangas T, Rissanen A (1999) Glycaemic Control in Patients with diabetes in Finland. Diabetes Care 22 (4): 575-9.

Watkins, PJ. (1993): The ABC of Diabetes. 3rd edition. BMJ Publication group.

Wokoma FS (1999). Hypertension in non - insulin dependent diabetic Nigerian. Diab. Int. 1999: 9:57 - 8. 